\title{
Key Factors Affecting the Flesh Flavor Quality and the Nutritional Value of Grass Carp in Four Culture Modes
}

\author{
Junming Zhang ${ }^{1,2, \dagger}$, Gen Kaneko ${ }^{3,+}+\mathbb{D}$, Jinhui Sun ${ }^{2,+}$, Guangjun Wang ${ }^{1}$, Jun Xie ${ }^{1}$, Jingjing Tian ${ }^{1}$, Zhifei Li ${ }^{1}$, \\ Wangbao Gong ${ }^{1}$, Kai Zhang ${ }^{1}$, Yun $\mathrm{Xia}^{1}$ and Ermeng Yu ${ }^{1, * \mathbb{D}}$ \\ 1 Guangdong Provincial Key Laboratory of Aquatic Animal Immune Technology, Pearl River Fisheries \\ Research Institute, CAFS, Guangzhou 510380, China; 1904028161@stu.tjau.edu.cn (J.Z.); \\ gjwang@prfri.ac.cn (G.W.); xj@prfri.ac.cn (J.X.); tianjj@prfri.ac.cn (J.T.); lzf@prfri.ac.cn (Z.L.); \\ gwb@prfri.ac.cn (W.G.); zk@prfri.ac.cn (K.Z.); xy@prfri.ac.cn (Y.X.) \\ 2 Tianjin Key Lab of Aqua-Ecology and Aquaculture, Tianjin Agricultural University, Tianjin 300384, China; \\ jhsun1008@tju.edu.cn \\ 3 School of Arts \& Sciences, University of Houston-Victoria, Victoria, TX 77901, USA; KanekoG@uhv.edu \\ * Correspondence: yem@prfri.ac.cn; Tel.: +86-20-8161-6178 \\ + These authors have contributed equally to this work.
}

check for

updates

Citation: Zhang, J.; Kaneko, G.; Sun,

J.; Wang, G.; Xie, J.; Tian, J.; Li, Z.;

Gong, W.; Zhang, K.; Xia, Y.; et al.

Key Factors Affecting the Flesh

Flavor Quality and the Nutritional Value of Grass Carp in Four Culture Modes. Foods 2021, 10, 2075. https:// doi.org/10.3390/foods10092075

Academic Editor: Luis Guerrero Asorey

Received: 3 August 2021

Accepted: 31 August 2021

Published: 2 September 2021

Publisher's Note: MDPI stays neutral with regard to jurisdictional claims in published maps and institutional affiliations.

Copyright: (c) 2021 by the authors. Licensee MDPI, Basel, Switzerland. This article is an open access article distributed under the terms and conditions of the Creative Commons Attribution (CC BY) license (https:// creativecommons.org/licenses/by/ $4.0 /)$.

\begin{abstract}
Flavor and nutritional value are important qualities of freshwater fish products, but the key factors affecting these quality parameters remain unclear. In this study, four typical aquaculture modes, including the commercial feed treatment (control), faba bean treatment (FBT), grass powder treatment (GPT), and waving water treatment with commercial feed (WWT), were used to explore the regulatory effect of water quality and feed (eaten and uneaten) on the flesh flavor and nutrition in grass carp (Ctenopharyngodon idella), a freshwater fish of the largest global production. During the culture period (90 days), water quality parameters of the four modes were measured every 15 days, and the flavor quality was evaluated by volatile flavor compounds detection and electronic nose analyzer. Flesh crude protein, crude fat, free fatty acid and free amino acid profiles were also determined. The results showed that, in the late period, the FBT mode had the poorest water quality with highest concentrations of nitrite and nitrate, while the GPT mode has the best water quality among the four modes. Most flesh flavor compounds found in the flesh of the control, GPT and WWT modes were pleasant. In the FBT mode with the poorest water quality, on the other hand, we found lower flavor quality (higher contribution of fishy compounds), higher water content, and lower contents of crude protein, crude fat, free fatty acids and free amino acids, compared to the other three modes. Correlation analyses showed that nitrite and nitrate are probably key water quality factors affecting the flavor quality and nutritional values besides eaten feed and uneaten feed factors. This study can serve as an important reference for ecological regulation and feeding administration of flesh quality in freshwater aquaculture fish.
\end{abstract}

Keywords: flavor quality; nutritional value; water quality factors; grass carp modes

\section{Introduction}

Grass carp (Ctenopharyngodon idella), with the highest global production in freshwater species, has provided inexpensive and high-quality animal protein for consumers [1]. It is well known that flavor and nutritional value are representative indicators of fish quality [2]. In the case of freshwater fish products, consumers tend to prefer products with less flavor and high nutritional value. Although there are several compounds that contribute to favorable flavor, volatile compounds are major contributors to flavor in aquatic products and are thus key factors for consumer acceptance [3,4]. The fish nutritional value indexes mainly include crude protein, crude lipid, fatty acids and amino acids, which are major nutritional components as human food [2]. Therefore, improving flavor quality and nutritional value can effectively enhance the market value of grass carp. The number of 
attempts to improve the flavor quality and nutritional value of fish is in ascent. It has been reported that dietary plant protein and oil sources significantly reduce the contents of the volatiles and improve the nutritional value in fillets of gilthead sea bream [5]. Low level of dietary fish meal $(25 \%)$ changes the volatile profiles in cooked fillets of farmed large yellow croaker [6]. The dietary lipid sources (fish oil and krill oil) help to produce more pleasant flavors by increasing the relative levels of 3-methylbutanal, heptanal, benzaldehyde and nonanal in crab muscle, and the diets with marine oil elevate polyunsaturated fatty acids in muscle [7]. In addition to the dietary intervention, water manipulation also affects the flavor of fish. Placing fish in clean water (off-flavor-free) has effectively removed off-odors in various fish species [8]. Several water quality factors (nitrite and ammonia) have been associated with the growth and nutritional value of grass carp $[9,10]$. However, the effects of water quality factors on flavor quality have seldom been reported. Therefore, further exploration of key water quality factors affecting the flavor quality together with nutritional value will be of great significance for the improvement of freshwater fish quality.

Grass carp culture in China has about 1100 years of history with accumulated farming experience. Now, besides the traditionally-developed commercial feed treatment mode, several novel aquaculture modes have been formed and applied in China, including the faba bean treatment (FBT) mode, grass powder treatment (GPT) mode and waving water treatment aquaculture (WWT) mode. The FBT mode refers to feeding grass carp with faba beans, which leads to higher flesh collagen content and better textual quality [11]. The GPT mode refers to feeding grass carp with grass powder, and the carp cultured by this mode has a bright body surface and sweet flesh [12]. In the WWT mode, grass carp is cultured with traditional commercial feeds and the use of water pumps to make the water surge and gain the advantage of compact flesh [13]. According to practical experience, in the late aquaculture period, both water quality and flesh quality become distinct in these aquaculture modes. Therefore, previous studies exploring the effect of diets on flesh nutritional value in each aquaculture mode should be one-sided. Water quality could be another important factor that accounts for the difference in the flesh flavor quality and nutritional value between these aquaculture modes.

In the present study, combined with the production practice, four typical aquaculture modes in China were simulated: FBT, GPT, WWT and commercial feed treatment (control). We monitored time-dependent changes in water quality parameters during the culture period of 90 days and evaluated flavor quality by volatile flavor compounds detection and an electronic nose analyzer. Nutritional value indexes including crude protein, crude fat, free fatty acids and free amino acids were also determined. Pearson correlation analysis was used to determine the key factors affecting flavor quality and nutritional value.

\section{Materials and Methods}

\subsection{Fish Culture and Four Treatment Modes}

The feeding trial was performed for 90 days in the culture base of Pearl River Fisheries Research Institute. In this study, four typical aquaculture modes were simulated, including the commercial feed treatment (control), faba bean treatment (FBT), grass powder treatment (GPT) and waving water treatment with commercial feed (WWT). The nutritional composition of these experimental diets are shown in Table 1 . The fish were cultured in 12 cement pools $(2.5 \mathrm{~m} \times 2.5 \mathrm{~m} \times 1.8 \mathrm{~m})$ (three pools for each mode, and 10 fish in each pool). There was no significant difference for the initial weight $(838 \pm 40 \mathrm{~g})$ between all groups $(p>0.05)$. The fish were fed at 9:00 and 16:00 every day. The daily feeding amount of both commercial feed and faba bean was $200 \mathrm{~g}$ and that of grass powder was $400 \mathrm{~g}$. Food residues were collected on the $15 \mathrm{~d}, 30 \mathrm{~d}, 45 \mathrm{~d}, 60 \mathrm{~d}, 75 \mathrm{~d}$ and $90 \mathrm{~d}$, respectively. The total amount of food residues of different diets was as follows: the control with $168 \mathrm{~g}$ of residues, FBT with $1620 \mathrm{~g}$ of residues, GPT with $890 \mathrm{~g}$ of residues and WWT with $183 \mathrm{~g}$ of residues. Culture conditions were the same in all pools: water temperature $25-30^{\circ} \mathrm{C}, \mathrm{pH} 6.5-7.5$, and the dissolved oxygen $>5.0 \mathrm{mg} / \mathrm{L}$. Generally, in the practical culture process, the frequency 
of water exchange in grass carp culture ponds is once every 3-4 months. Thus, water in these pools were not exchanged during the culture period ( 90 days) in the present study.

Table 1. Nutritional composition of different diets.

\begin{tabular}{ccccc}
\hline & Crude Protein $\mathbf{( g / 1 0 0 ~ g ) ~}$ & Crude Fat (g/100 g) & Ash (g/100 g) & Moisture $(\mathbf{g} / \mathbf{1 0 0} \mathbf{~ g )}$ \\
\hline Commercial diet & 28.8 & 5.5 & 8.1 & 10.9 \\
Faba bean & 28 & 1.4 & 4.1 & 14.4 \\
Grass powder & 14.1 & 1.8 & 10.8 & 12.9 \\
\hline
\end{tabular}

\subsection{Detection of Water Quality Parameters}

According to a previous study [14], water quality parameters were measured using a microtiter plate reader. Nitrate nitrogen $\left(\mathrm{NO}_{3}-\mathrm{N}\right)$ was measured with the phenol disulfonic acid method. Nitrite nitrogen $\left(\mathrm{NO}_{2}-\mathrm{N}\right)$ was measured with the Griess-Saltzman method. Total ammonia nitrogen (TAN) concentrations were measured with the spectrophotometric method with salicylic acid. Soluble reactive phosphorus $\left(\mathrm{PO}_{4}-\mathrm{P}\right)$ was measured with the molybdenum blue method. Total nitrogen (TN) and total phosphorus (TP) were measured using the potassium persulfate digestion method. All water quality parameters were determined every 15 days during the experimental period.

\subsection{Sample Collection}

After 90 days, the fish were fasted for $24 \mathrm{~h}$, and three fish were sampled from each group. The fish were individually euthanized in $\mathrm{pH}$-buffered tricaine methanesulfonate $(250 \mathrm{mg} / \mathrm{L})$ and the body weight and body length were measured. This fish study has a waiver of approval the from ethics committee in conformity with Chinese law. The muscle samples were used to measure volatile aroma components, the contents of water, crude protein and crude fat, free fatty acid and free amino acid profiles. The skin samples were used to determine volatile component. Growth-related parameters were calculated as follows.

$$
\text { Weight gain rate }(\text { WGR, \% })=(\text { final weight }- \text { initial weight }) / \text { initial weight } \times 100
$$

$$
\text { Condition factor }(\mathrm{CF}, \%)=\text { body weight } / \text { length }^{3} \times 100
$$

\subsection{Determination of Nutritional Value Indexes}

In the present study, the methods of the State Standard of the People's Republic of China (GB5009.4-2016) were used to determine the contents of water (directly drying method), crude protein (Kjedahl method), crude fat (Soxhlet extraction method), free fatty acid contents (acid hydrolysis method) and free amino acid contents (acetyl chloridemethanol and transesterification).

\subsection{Determination of Volatile Aroma Components}

The volatile aroma components of muscle and skin of grass carp were sampled by using solid phase microextraction (SPME) [15]. Volatile compounds were analyzed on a GCMS apparatus (Shimadzu-QP2010, Kyoto, Japan) operating in the electron ionization mode $(\mathrm{EI}, 70 \mathrm{eV})$. The extracted analytes were thermally desorbed by inserting the SPME fiber to the gas chromatograph injector, kept at $250{ }^{\circ} \mathrm{C}$ and then separated on a HP-INNOWAX capillary column $(30 \mathrm{~m} \times 0.25 \mathrm{~mm} \times 0.25 \mu \mathrm{m}$, J\&W Scientific Inc., Folsom, CA, USA). The elution program temperatures used during analyses were as follows: (i) $60{ }^{\circ} \mathrm{C}$ for $5 \mathrm{~min}$, (ii) increase in temperature with a heating rate of $3.5^{\circ} \mathrm{C} / \mathrm{min}$ up to $100^{\circ} \mathrm{C}$ for $5 \mathrm{~min}$, (iii) increase in temperature with a heating rate of $8{ }^{\circ} \mathrm{C} / \mathrm{min}$ up to $200^{\circ} \mathrm{C}$ for $5 \mathrm{~min}$, and (iv) increase in temperature with a heating rate of $15^{\circ} \mathrm{C} / \mathrm{min}$ up to $280^{\circ} \mathrm{C}$ for $15 \mathrm{~min}$. The carrier gas (He) flow rate was $1.2 \mathrm{~mL} / \mathrm{min}$.

Volatile compounds of muscle and skin were identified in the full scan mode $(m / z 30-550)$ by NIST mass spectral library (NIST14, version 2.2, National Institute of Standards and 
Technology, Gaithersburg, MD, USA). Volatile compounds were tentatively identified using the GC-MS spectra. Compounds with $\leq 80 \%$ similarity to the NIST library were not considered. In addition, identification was performed by matching their Kovats indices (KI) determined relative to the retention time of a series of n-alkanes (C8-C20) with linear interpolation, with those of authentic compounds or literature data. The chromatographic responses of the detected volatile compounds (peak area counts) were monitored and compared among the studied samples. The relative content of the components were determined with the peak area normalization method.

\subsection{Analysis of Relative Odor Activity Values}

The odor activity value (OAV) reflects the contribution of a single compound to olfaction. This study adopted the relative OAV (ROAV) method, in which the ROAV of less than 1 indicates that the substance has a small contribution to the odor, and a value greater than 1 indicates a significant contribution to the odor [16]. The component making the greatest contribution to the odor of the sample is defined as $\mathrm{ROAV}_{\text {stan }}$ and given a value of 100, with the ROAV of other volatile components being calculated as follows:

$$
R O A V_{i} \approx 100 \times \frac{C_{i}}{C_{\text {Stan }}} \times \frac{T_{\text {stan }}}{T_{i}}
$$

where $C_{i}$ and $T_{i}$ represent the relative content (the percentage of each compound peak intensity to total peak intensity of all compounds) and the sensory threshold of each volatile component, respectively. $C_{\text {stan }}$ and $T_{\text {stan }}$ represent the relative contents and the sensory thresholds, respectively, of the components contributing most to the total odor of the sample.

\subsection{Analysis of Flavor Characteristics}

According to a previous study [17], $5 \mathrm{~g}$ of back muscle and $5 \mathrm{~g}$ of skin were collected and homogenized with $2 \mathrm{~mL} 0.18 \mathrm{~g} / \mathrm{mL} \mathrm{NaCl}$ solution. The mixture was weighed accurately in a 5-mL electronic nose automatic sampling bottle. It was then incubated at $60{ }^{\circ} \mathrm{C}$ for $10 \mathrm{~min}$ with the cap of the bottle tightened. The clean and dry air was used as the carrier gas at a flow rate of $150 \mathrm{~L} / \mathrm{min}$. The injection volume was $2500 \mu \mathrm{L}$, injection needle temperature was $55^{\circ} \mathrm{C}$, and data acquisition time was $120 \mathrm{~s}$. The cleaning time of the sensor was $1080 \mathrm{~s}$ and 8 fish samples were evaluated in parallel.

\subsection{Statistical Analysis}

All statistical analysis was performed using IBM SPSS Statistics 23 (SPSS Inc., Chicago, IL, USA). Data were analyzed by one-way analysis of variance (ANOVA) followed by Tukey's test. A $p$ value of less than 0.05 was considered as a significant difference. The results were presented as mean $\pm \mathrm{SE}$.

Pearson's correlation was used for correlation analysis between affecting factors (water quality factors, feed) and flavor quality (volatile compounds). Meanwhile, the correlations between affecting factors and nutrients were also analyzed. The feed factors include the amount of eaten feed (feed intake by fish) and uneaten feed (feed residues in water). The clustering algorithm adopted Ward's minimum variance method. A twosided $p$ value $<0.05$ was considered statistically significant. Correlation analyses were performed by using the open-source Hiplot platform [18].

\section{Results}

\subsection{Water Quality Analysis}

The changes in water quality parameters are shown in Figure 1. All parameters showed an upward trend during the 90 days of the experimental period. The upward trends of total ammonia nitrogen, total nitrogen, soluble reactive phosphorus and total phosphorus were consistent in the four culture modes, while the trends of nitrate and nitrite were different depending on the modes (Figure 1a,b). The accumulations of nitrate 
and nitrite in the FBT mode were the most significant among the culture modes. At $90 \mathrm{~d}$, the nitrate content in the FBT mode was $9.52 \pm 0.23 \mathrm{mg} / \mathrm{L}$, while those of control group, GPT and WWT modes were $4.41 \pm 0.07 \mathrm{mg} / \mathrm{L}, 3.99 \pm 0.05 \mathrm{mg} / \mathrm{L}$ and $7.18 \pm 0.11 \mathrm{mg} / \mathrm{L}$, respectively. Similarly, the nitrite content in the FBT mode increased to $1.08 \mathrm{mg} / \mathrm{L}$ at $90 \mathrm{~d}$, while those in other three modes were $0.45 \pm 0.039 \mathrm{mg} / \mathrm{L}$ (control), $0.15 \pm 0.002 \mathrm{mg} / \mathrm{L}$ (GPT) and $0.23 \pm 0.004 \mathrm{mg} / \mathrm{L}(\mathrm{WWT})$, respectively.

a

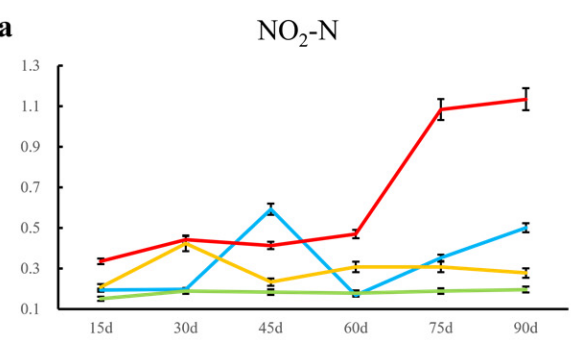

d

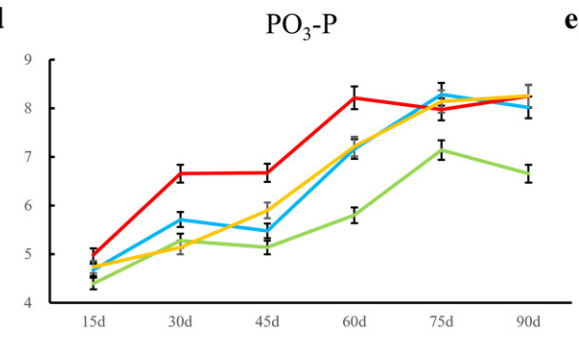

b

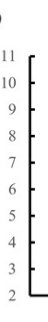

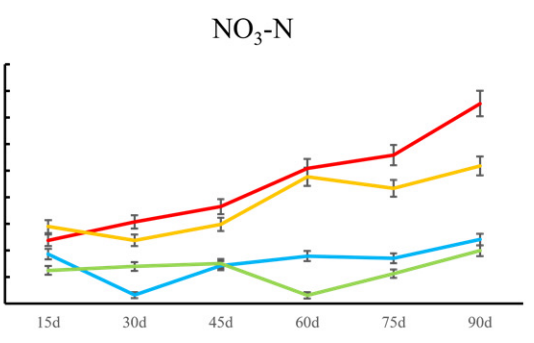

e

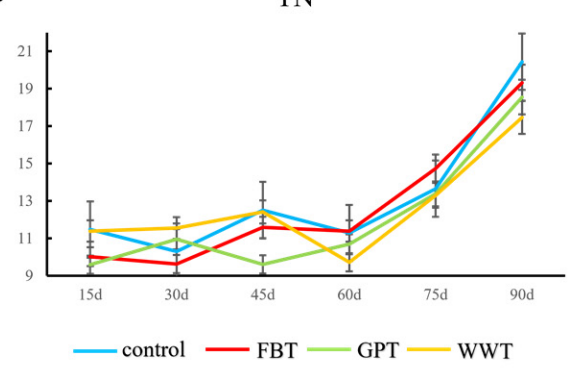

c TAN

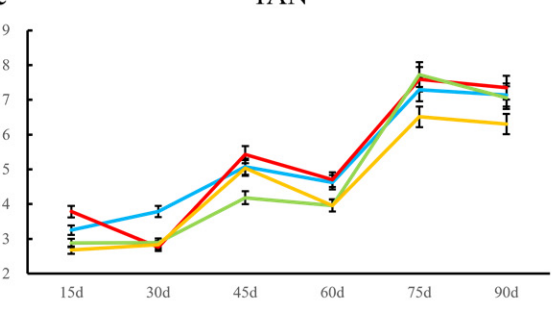

$\mathrm{TP}$

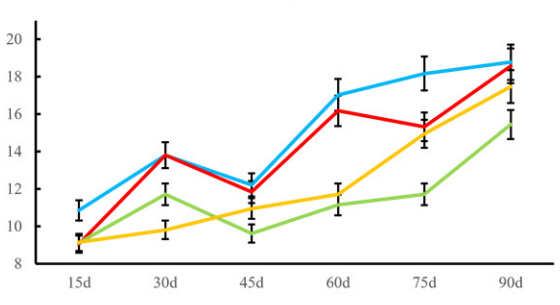

Figure 1. The time-dependent changes of six water quality parameters in the four culture modes. (a) $\mathrm{NO}_{2}-\mathrm{N}$, nitrite nitrogen; (b) $\mathrm{NO}_{3}-\mathrm{N}$, nitrate nitrogen; (c) TAN, total ammonia nitrogen; (d) $\mathrm{PO}_{4}-\mathrm{P}$, soluble reactive phosphorus; (e) TN, total nitrogen; (f) TP, total phosphorus. FBT, faba bean treatment; GPT, grass powder treatment; WWT, waving water treatment with commercial feed.

\subsection{Growth Performance and Nutrition Composition}

The growth performance of grass carp was significantly different under four modes (Table 2). The control showed the highest weight gain rate and condition factor, while FBT had a lower weight gain rate and condition factor than other treatments. According to Figure 2, the contents of crude protein, crude fat and free fatty acids in the muscle of grass carp were lower in the FBT mode than those in other modes. The water content in the FBT mode was the highest among all modes. The contents of free fatty acids detected were slightly different; the GPT and FBT modes had the highest and lowest contents, respectively (Figure $2 \mathrm{~d}$ ). The different trends for crude fat and free fatty acids between groups are probably because crude fat includes not only free fatty acids but also triglyceride, cholesterol, etc., which were not determined in this study. All amino acids detected showed the lowest content in the FBT mode. Concentrations of some taste-active amino acids, glutamate, aspartate and alanine are shown in Figure 2e, and all detected amino acids are shown in Table S1.

Table 2. Growth performance of grass carp in different modes.

\begin{tabular}{lcccc}
\hline & Control & FBT & GBT & WWT \\
\hline Weight gain rate (\%) & $34.61 \pm 0.64^{\mathrm{a}}$ & $7.52 \pm 0.73^{\mathrm{d}}$ & $19.62 \pm 1.83^{\mathrm{c}}$ & $30.58 \pm 1.96^{\mathrm{b}}$ \\
Condition factor (\%) $^{\mathrm{a}}$ & $33.41 \pm 2.7^{\mathrm{a}}$ & $27.18 \pm 1.41^{\mathrm{b}}$ & $29.55 \pm 0.81^{\mathrm{a}, \mathrm{b}}$ & $32.61 \pm 3.01^{\mathrm{a}}$ \\
\hline
\end{tabular}

Note: Values of the same row with different superscript letters were significantly different. 
a

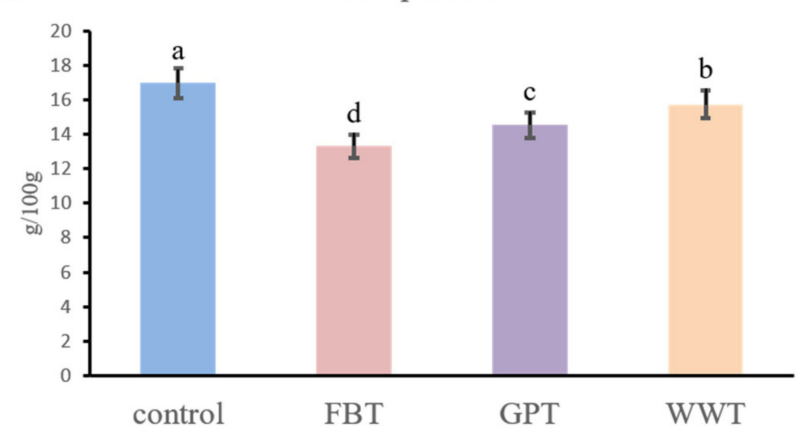

c

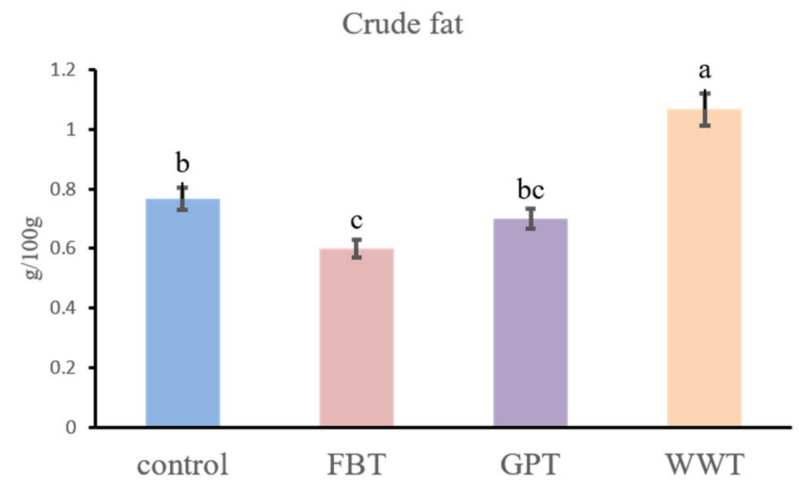

b

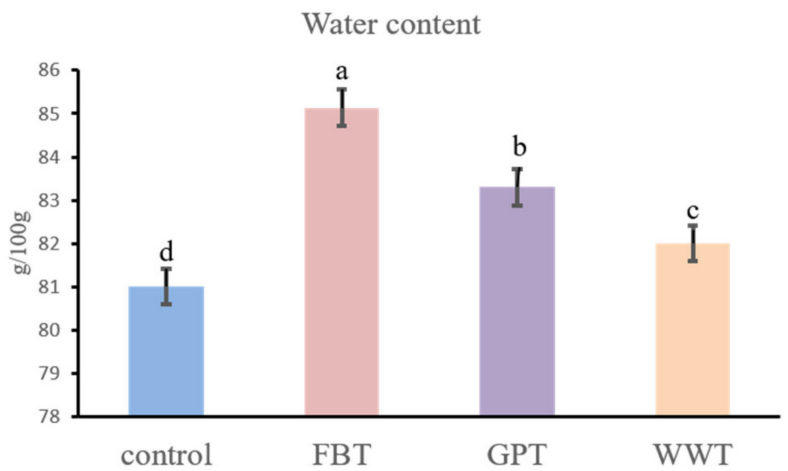

d

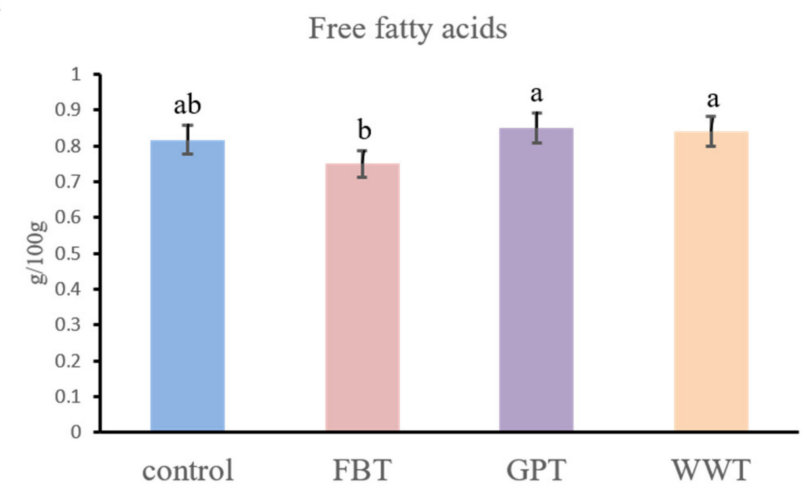

e

\begin{tabular}{|c|c|c|c|c|}
\hline & Control(mg/100g) & FBT(mg/100g) & GPT(mg/100g) & WWT(mg/100g) \\
\hline Glutamate & $5.3 \pm 0.2^{\mathrm{b}}$ & $3.6 \pm 0.2^{\mathrm{d}}$ & $6.6 \pm 0.1^{\mathrm{a}}$ & $4.6 \pm 0.3^{\mathrm{c}}$ \\
\hline Aspartate & $0.45 \pm 0.05^{\mathrm{b}}$ & $0.37 \pm 0.01^{\mathrm{c}}$ & $0.56 \pm 0.03^{\mathrm{a}}$ & $0.59 \pm 0.04^{\mathrm{a}}$ \\
\hline Alanine & $23 \pm 1^{\mathrm{a}}$ & $13 \pm 1^{\mathrm{b}}$ & $16 \pm 2^{\mathrm{b}}$ & $20 \pm 1^{\mathrm{a}}$ \\
\hline
\end{tabular}

Figure 2. Nutrition composition of grass carp muscle from four culture modes. Statistical analyses were performed using Tukey's test. FBT, faba bean treatment; GPT, grass powder treatment; WWT, waving water treatment with commercial feed. (a) Crude protein; (b) Water content; (c) Crude fat; (d) Free fatty acids; (e) free amino acids. Different superscript letters were significantly different $(p<0.05)$.

\subsection{Analysis of Volatile Compounds}

GC-MS was utilized to analyze the volatile compounds in grass carp cultured in the four modes (Table S2-S5). In the control, the numbers of volatile compounds identified in muscle and skin samples were 29 and 22, respectively. Muscle/skin samples from the FBT, GPT and WWT modes identified 33/35, 24/34 and 30/30 volatile compounds, respectively.

The common volatile compounds include 1-octene-3-ol detected in all tested samples and nonanal and 1-octanol detected in all samples except for the muscle sample of the FBT mode. In the muscle samples of the control (Table S2), the relative percentage contents of nonanal (23.67\%) and 2,4,6-Trimethylmandelic acid (21.12\%) were the highest, while in the skin samples, 1-Octen-3-ol, dihydrocoumarin, 4,4,5,7,8-pentamethyl, 1-octanol and nonanal accounted for the highest percentages (8.12-21.11\%). In the FBT mode (Table S3), the relative contents of nonanal, hexanal and hexadecanal were the highest (7.63-17.05\%), and those of nonanal, 2-cyclohexen-1-ol and (E)-2-nonenal were the highest in the skin sample (5.96-15.96\%). In the muscle samples of the GPT mode (Table S4), the relative contents of hexadecanal, nonanal and p-isopropoxyaniline were the highest (8.07-20.01\%), and those of 1-octen-3-ol, carbamodithioic acid, diethyl-, methyl ester and formamide, N,Ndibutyl- were the highest in the skin sample (7.80-16.70\%). Lastly, in the muscle samples of 
the WWT mode (Table S5), the relative contents of 2,3-octanedione, hexyl chloroformate, nonanal were the highest (8.44-13.18\%), while in the skin sample, the relative contents of the 1-octen-3-ol, carbamodithioic acid, diethyl-, methyl ester and formamide, N,N-dibutylwere the highest (11.91-24.79\%).

\subsection{Analysis of Key Flavor Components}

The flavor components were further analyzed using the ROAV method, in which a larger ROAV indicates a greater contribution of the components to the overall flavor of the sample. As shown in Table 3, the main flavor components (ROAV > 1) of the control, GPT and WWT modes were similar, while those of the FBT mode were significantly different. In the FBT mode, the main flavor components of muscle sample were nonanal, (E)-2-decenal, 1-octen-3-ol, 1-butanol and hexanal, and the main flavor components of skin sample were (E)-2-nonenal, (E,E)-2,4-decadienal, (E,E)-2,4-nonadienal, (E)-2-decenal, nonanal and octanal. The odor attribute of (E)-2-octenal is fatty, and the odor attribute of (E)-2-nonenal, (E,E)-2,4-decadienal and (E,E)-2,4-nonadienal is a fishy off-flavor, indicating that the main flavor of the flesh in the FBT mode was fishy and fatty. On the other hand, the odors of other modes were mushroom, fatty and grass. These results suggested that grass carp in the FBT mode has the worst odor.

\subsection{Flavor Characteristics Analysis}

The E-nose analysis was used to analyze the flavor characteristics of the flesh samples. The Figure 3 shows the results of principal component analysis (PCA) on the samples from the four modes. The PCA of the four fish muscle samples showed that the sum of the contribution rates of the first $(71.84 \%)$ and second $(26.70 \%)$ principal components was $98.54 \%$, which basically covered most of the original information of the samples. The difference between the four modes was mainly attributed to the first principal component in muscle (Figure 3a). Consistent with the results in Table 3, the flavor characteristics of control, GPT and WWT modes were similar. The PCA results of skin sample were consist with those of muscle samples (Figure $3 b$ ). 
Table 3. Main flavor compounds of muscle and skin samples in four culture modes.

\begin{tabular}{|c|c|c|c|c|c|c|c|c|c|c|c|c|c|c|c|c|c|c|}
\hline \multirow{3}{*}{ Compound } & \multirow{3}{*}{ Threshold $(\mu \mathrm{g} / \mathrm{kg})$} & \multirow{3}{*}{ Odor Attributes } & \multicolumn{4}{|c|}{ Control } & \multicolumn{4}{|c|}{ FBT } & \multicolumn{4}{|c|}{$\begin{array}{l}\text { GPT } \\
\end{array}$} & \multicolumn{4}{|c|}{ WWT } \\
\hline & & & \multicolumn{2}{|c|}{ Relative Content $(\%)$} & \multicolumn{2}{|c|}{ ROAV } & \multicolumn{2}{|c|}{ Relative Content (\%) } & \multicolumn{2}{|c|}{ ROAV } & \multicolumn{2}{|c|}{ Relative Content (\%) } & \multicolumn{2}{|c|}{ ROAV } & \multicolumn{2}{|c|}{ Relative Content (\%) } & \multicolumn{2}{|c|}{ ROAV } \\
\hline & & & $\begin{array}{l}\text { Muscle } \\
\text { Sample }\end{array}$ & $\begin{array}{c}\text { Skin } \\
\text { Sample }\end{array}$ & $\begin{array}{l}\text { Muscle } \\
\text { Sample }\end{array}$ & $\begin{array}{c}\text { Skin } \\
\text { Sample }\end{array}$ & $\begin{array}{l}\text { Muscle } \\
\text { Sample }\end{array}$ & $\begin{array}{c}\text { Skin } \\
\text { Sample }\end{array}$ & $\begin{array}{l}\text { Muscle } \\
\text { Sample }\end{array}$ & $\begin{array}{c}\text { Skin } \\
\text { Sample }\end{array}$ & $\begin{array}{l}\text { Muscle } \\
\text { Sample }\end{array}$ & $\begin{array}{c}\text { Skin } \\
\text { Sample }\end{array}$ & $\begin{array}{l}\text { Muscle } \\
\text { Sample }\end{array}$ & $\begin{array}{c}\text { Skin } \\
\text { Sample }\end{array}$ & $\begin{array}{l}\text { Muscle } \\
\text { Sample }\end{array}$ & $\begin{array}{c}\text { Skin } \\
\text { Sample }\end{array}$ & $\begin{array}{l}\text { Muscle } \\
\text { Sample }\end{array}$ & $\begin{array}{c}\text { Skin } \\
\text { Sample }\end{array}$ \\
\hline 1-Octen-3-ol & 1.0 & Mushroom & 0.99 & $\begin{array}{l}21.11 \\
812\end{array}$ & $\begin{array}{r}3.703 \\
88329 * *\end{array}$ & $\begin{array}{r}100^{*} \\
38483 * *\end{array}$ & $\begin{array}{l}2.40 \\
5.58\end{array}$ & 5 & $\begin{array}{l}30.572 * \\
327274 *\end{array}$ & 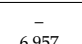 & 2.63 & 16.17 & $30.306^{*}$ & $96.820 *$ & 9.28 & 24.79 & $\begin{array}{l}100^{*} \\
80987^{*}\end{array}$ & 100 \\
\hline Decanal & 0.1 & Grass & 2.68 & - & $100^{*}$ & - & - & 0.66 & - & 8.800 & - & - & - & - & - & 0.58 & - & 23.448 \\
\hline $\begin{array}{l}\text { Eucalyptol } \\
\text { Hetranal }\end{array}$ & 3.0 & $\begin{array}{l}\text { Chemical } \\
\text { Green }\end{array}$ & 1.84 & - & 2.293 & - & - & 136 & - & -- & - & - & - & - & - & - & - & - \\
\hline $\begin{array}{l}\text { Heptanal } \\
\text { Octanal }\end{array}$ & $\begin{array}{l}3.0 \\
0.7\end{array}$ & $\begin{array}{l}\text { Green } \\
\text { Green }\end{array}$ & - & $\overline{-}$ & - & - & - & $\begin{array}{l}1.36 \\
4.22\end{array}$ & - & $\begin{array}{l}0.607 \\
8009\end{array}$ & $\begin{array}{c}- \\
-\end{array}$ & $\begin{array}{l}0.57 \\
2.39\end{array}$ & - & $\begin{array}{l}1.134 \\
20407\end{array}$ & - & 0.89 & - & 1.199 \\
\hline $\begin{array}{l}\text { OCtanal } \\
\text { Tetradecanal }\end{array}$ & $\begin{array}{l}0.7 \\
110.0\end{array}$ & $\begin{array}{l}\text { Green } \\
\text { Fishy }\end{array}$ & $\overline{-}$ & $\overline{-}$ & $\overline{-}$ & $\overline{-}$ & - & 4.22 & - & ${ }^{8.099}$ & $\overline{-}$ & ${ }^{2.39}$ & $\overline{-}$ & -20.407 & $\begin{array}{c}-\overline{-} \\
2.61\end{array}$ & $\overline{-}$ & 0.255 & $\overline{-}$ \\
\hline $\begin{array}{l}\text { Ietradecanal } \\
\text { (E)-2-Octenal }\end{array}$ & $\begin{array}{l}11.0 \\
3.0\end{array}$ & $\begin{array}{l}\text { Fishy } \\
\text { Fatty }\end{array}$ & $\overline{-}$ & $\overline{-}$ & $=$ & $\overline{-}$ & 2.48 & 3.39 & 4.844 & 1.515 & $\begin{array}{l}- \\
-\end{array}$ & $\overline{-}$ & $\overline{-}$ & - & ${ }_{-2.61}^{2 .}$ & $\overline{-}$ & 0.250 & $\overline{-}$ \\
\hline $\begin{array}{l}\text { (E)-2-Decenal } \\
\text { (E)-Donal }\end{array}$ & 0.3 & $\begin{array}{l}\text { Fatty } \\
\text { Fint }\end{array}$ & - & - & - & - & 1.86 & $\begin{array}{l}5.96 \\
5.96\end{array}$ & $36.414^{*}$ & $26.666 *$ & - & - & - & - & - & - & - & - \\
\hline (E,E)-2,4-Decadienal & $\begin{array}{l}0.090 \\
0.070\end{array}$ & $\begin{array}{l}\text { Fishy, wax } \\
\text { Fishy }\end{array}$ & $\overline{-}$ & $\overline{-}$ & $\overline{-}$ & $\overline{-}$ & $=$ & $\begin{array}{l}2.05 \\
4.74\end{array}$ & $\overline{-}$ & $\begin{array}{l}30.097 * \\
90.87\end{array}$ & - & $=$ & - & - & - & - & - & - \\
\hline
\end{tabular}

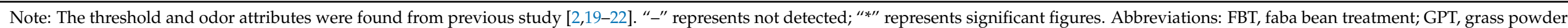
treatment; WWT, waving water treatment with commercial feed. 

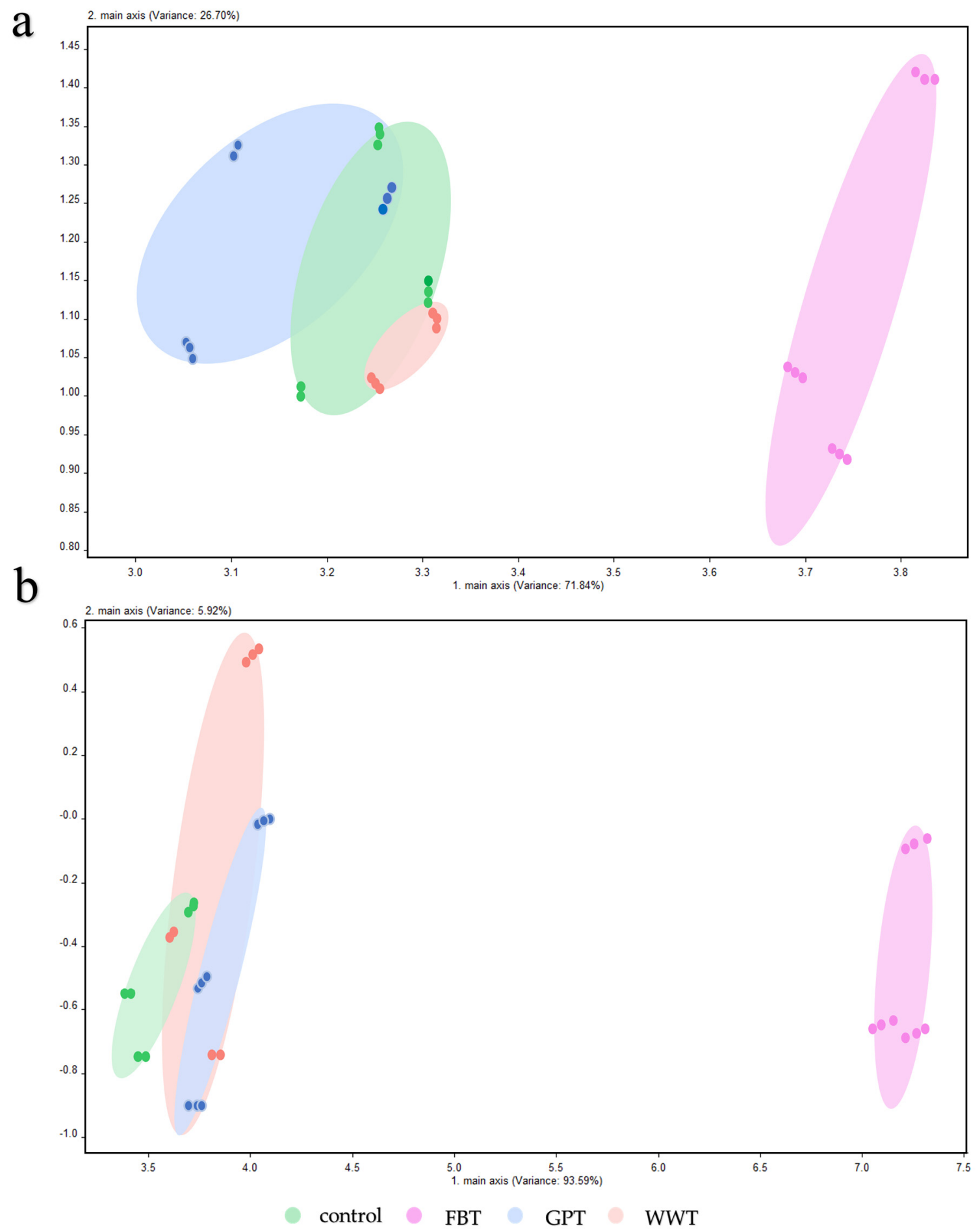

Figure 3. PCA analyses of flavor characteristics from the muscle (a) and skin (b) samples in the four modes. FBT, faba bean treatment; GPT, grass powder treatment; WWT, waving water treatment with commercial feed.

\subsection{Correlation Analysis}

In the present study, we analyzed the correlation between the affecting factors (water parameters and feed (eaten feed and uneaten feed)) and flesh quality. Figure 4a shows that both nitrite $(p<0.05$, correlation coefficients $=0.95)$ and nitrate $(p<0.05$, correlation coefficients $=0.84$ ) had a significant positive correlation with $(\mathrm{E}, \mathrm{E})-2,4$-decadienal, $(\mathrm{E}, \mathrm{E})$ - 
2,4-nonadienal, (E)-2-octenal and (E)-2-decenal, and these four compounds presented fishy odor and fatty odor. On the other hand, uneaten feed (feed residues in water) had a significant positive correlation with nitrite (correlation coefficients $=0.75$ ) and nitrate (correlation coefficients $=1$ ). These results demonstrated that nitrite, nitrate and uneaten feed were tightly connected with flavor quality.

a

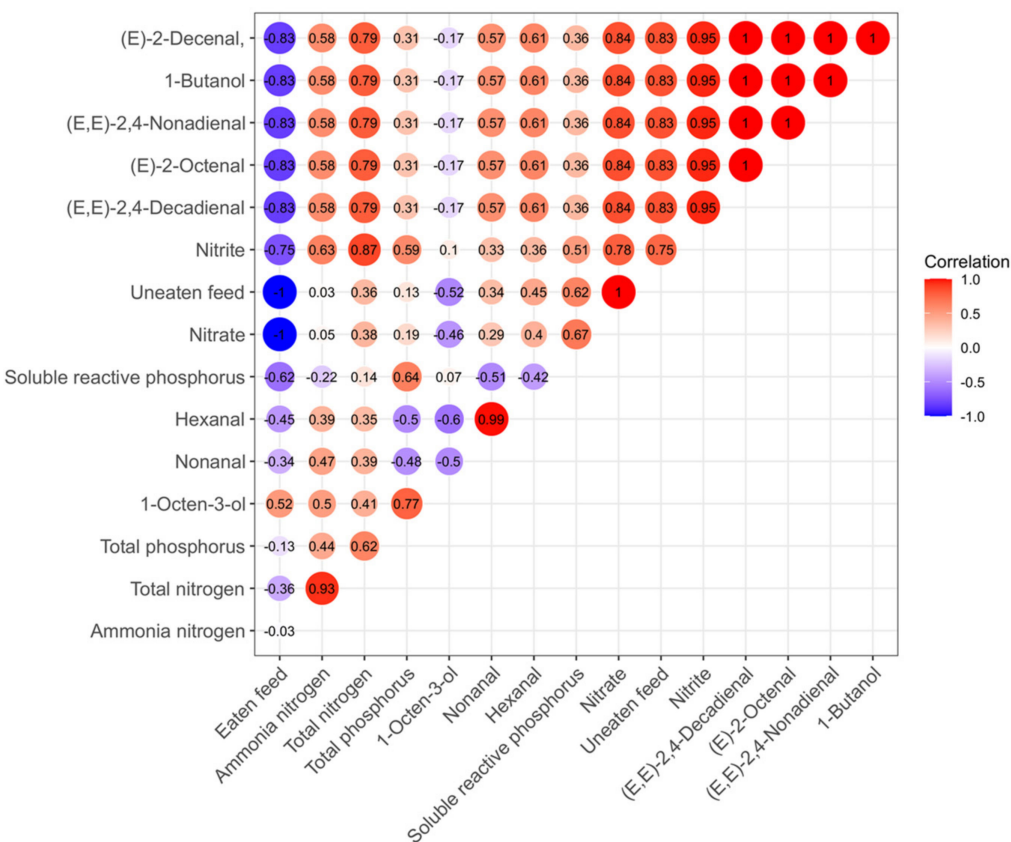

b

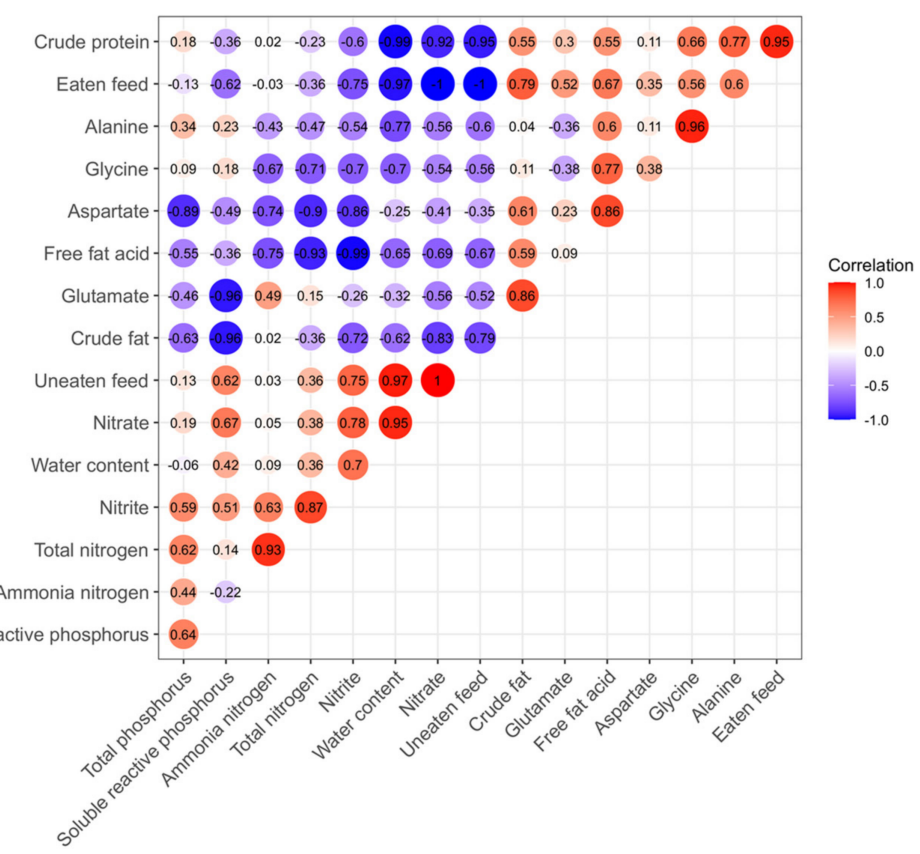

Figure 4. The correlation between flesh quality parameters (main flavor compounds (a) and nutritional values (b)) and affecting factors (water quality parameters and feed). Red represents a positive correlation, and blue represents a negative correlation. The numbers in the circle represent the correlation coefficient. 
According to Figure $4 \mathrm{~b}$, eaten feed (feed intake by fish) had significant positive correlation with crude protein $(p<0.05$, correlation coefficients $=0.95)$ and crude fat $(p<0.05$, correlation coefficients $=0.79)$. Moreover, eaten feed was positively correlated with the contents of some free amino acids (glutamate, aspartate and alanine). Glutamate and aspartate are known to have an umami taste [23], and alanine has a sweet taste [24]. These results suggested that eaten feed play essential roles in the determination of flesh nutritional value as well as taste characteristics.

\section{Discussion}

Flavor is an important index to evaluate the freshwater fish quality. The flavor quality can be judged according to the odor attribute and threshold value of volatile compounds. The present study demonstrated that the flavor quality of the control, GPT and WWT modes were similar to each other. In these three groups, 1-octen-3-ol, nonanal, hexanal and decanal were the main substances contributing to flavor. It has been reported that 1-octen3 -ol has a mushroom-like odor $[25,26]$. Nonanal was described to have a fatty aroma [2], and hexanal contributes to the green leafy odor of aquatic products [27]. These volatile substances are common in aquatic products and their odors are generally considered to be pleasant [28-31]. On the contrary, the odor composition of grass carp in the FBT mode was clearly different from those of other three modes (Table 3; Figure 4). The main flavor contribution substances of the FBT mode were (E)-2-decenal, (E)-2-nonenal, (E,E)2,4-nonadienal and (E,E)-2,4-decadienal. It has been reported that the odor descriptions of (E)-2-decenal, (E)-2-nonenal are fatty and moss [32], and the odors of (E,E)-2,4-nonadienal and (E,E)-2,4-decadienal have been described as a fishy smell [33]. It is thus likely that grass carp cultured in the FBT mode has a stronger fishy smell compared to those cultured in other three modes.

Taken together with the results of the water quality parameter analysis (Figure 1), it would be possible that grass carp cultured under poor water quality (high nitrate and high nitrite) have a poor flavor quality. Therefore, the regulation of water quality, especially nitrate and nitrite, could be crucial for improving the quality of grass carp. In the future, the actual effects of nitrate and nitrite should be verified by setting different concentration gradients of nitrate and nitrite in the grass carp culture. Moreover, the effect of feed residues (uneaten feed) on water quality cannot be ignored. It has been reported that the accumulation of feed residues in the culture pond led to the increase of content of ammonia nitrogen and nitrite [34]. In addition, the water quality factors such as nitrate and nitrite are related to disease $[35,36]$, immunity $[37,38]$ and metabolism $[39,40]$ and should be carefully monitored in aquaculture.

Diet is the direct cause of the changes in water quality during fish farming. The poor water quality in the FBT mode is likely to be attributed to uneaten faba beans in the water. Furthermore, faba beans may contain proteins that cannot be efficiently metabolized by grass carp, which causes the accumulation of nitrate and nitrite in water. Previous studies have shown that the nitrogen emission rate of fish feeding on faba bean is significantly higher than those of feeding on commercial diets [41]. Interestingly, in the FBT group, the concentrations of nitrate nitrogen $\left(\mathrm{NO}_{3}-\mathrm{N}\right)$, nitrite nitrogen $\left(\mathrm{NO}_{2}-\mathrm{N}\right)$ and total ammonia nitrogen (TAN) were the highest, but the total nitrogen concentration was the lowest. In this present study, the method for determining total nitrogen is potassium persulfate digestion method [14], and the total nitrogen determined by this method includes total inorganic nitrogen $\left(\mathrm{NO}_{3}-\mathrm{N}, \mathrm{NO}_{2}-\mathrm{N}\right.$ and TAN) and organic nitrogen. Thus, the reason why the content of total nitrogen in the FBT mode is not the highest could be that the content of organic nitrogen is lower than those in other modes. On the other hand, lower content of nitrogen in the water of the GPT mode was probably because of the low protein content in grass powder. A previous study also found that the water quality is better maintained after feeding on grass powder compared with commercial feed [42]. The overall features of water and flesh quality parameters of the WWT mode were similar to those of control, indicating the importance of diets in these parameters. 
It is worth noting that the nutritional composition of grass carp cultured in poor water quality was also the worst in this study. The contents of crude fat and free fatty acids in the FBT mode were lower than other modes, and this may also be related to the low fat content of faba beans [41]. Moreover, the content of glutamate, aspartate and alanine in the FBT mode was lower than those of other modes (Figure 2). These amino acids have been reported to contribute to umami taste [26]. The correlation between the water quality factors and flavor quality (substance for undesirable flavors and amino acids for pleasant taste) substantiated the important roles of nitrate and nitrite in the flavor quality of grass carp.

In conclusion, the present study preliminarily screened the water quality factors that affect the quality of grass carp, highlighting the importance of water nitrite and nitrate as well as eaten feed and uneaten feed. In practical production, adopting technical means to regulate the concentration of nitrate and nitrite in aquaculture water will be a potential method to improve the flavor quality of grass carp. Furthermore, this study demonstrated that feeding administration for eaten feed and uneaten feed would be an effective strategy for the quality improvement of grass carp. These results would provide reference materials for the improvement of flesh quality and consumer acceptance in other freshwater fish.

Supplementary Materials: The following are available online at https://www.mdpi.com/article/ 10.3390/foods10092075/s1, Table S1: The concentration of amino acids; Table S2: The volatile compounds of the control; Table S3: The volatile compounds of FBT mode; Table S4: The volatile compounds of GPT mode; Table S5. The volatile compounds of WWT mode.

Author Contributions: Conceptualization, E.Y.; methodology, G.K.; software, J.S.; validation, J.X. and Z.L.; formal analysis, J.T. and W.G.; investigation, J.Z.; resources, Y.X.; data curation, K.Z.; writing—original draft preparation, J.Z.; writing—review and editing, E.Y., G.K. and J.S.; supervision, J.X.; project administration, G.W.; funding acquisition, E.Y. All authors have read and agreed to the published version of the manuscript.

Funding: This study was funded by the National Key R\&D Program of China (2019YFD0900303), the Guangdong Basic and Applied Basic Research Foundation (2021A1515011178) and China Agriculture Research System of MOF and MARA (No. CARS-45-21).

Institutional Review Board Statement: The experimental protocols used in this study were approved by the Laboratory Animal Ethics Committee of Pearl River Fisheries Research Institute, CAFS, China, under permit number LAEC-PRFRI-2020-11-22.

Conflicts of Interest: The authors declare no conflict of interest.

\section{References}

1. Tian, J.; Zhang, J.; Yu, E.; Sun, J.; Xia, Y.; Zhang, K.; Li, Z.-F.; Gong, W.; Wang, G.; Xie, J. Identification and analysis of lipid droplet-related proteome in the adipose tissue of grass carp (Ctenopharyngodon idella) under fed and starved conditions. Comp. Biochem. Physiol. Part D Genom. Proteom. 2020, 36, 100710.

2. Cai, L.; Tong, F.; Tang, T.; Ao, Z.; Wei, Z.; Yang, F.; Shu, Y.; Liu, S.; Mai, K. Comparative evaluation of nutritional value and flavor quality of muscle in triploid and diploid common carp: Application of genetic improvement in fish quality. Aquaculture 2021, 541, 736780. [CrossRef]

3. Liu, Y.; Huang, Y.; Wang, Z.; Cai, S.; Zhu, B.; Dong, X. Recent advances in fishy odor in aquatic fish products, from formation to control. Int. J. Food Sci. Technol. 2021. [CrossRef]

4. Selli, S.; Rannou, C.; Prost, C.; Robin, J.; Serot, T. Characterization of Aroma-Active Compounds in Rainbow Trout (Oncorhynchus mykiss) Eliciting an Off-Odor. J. Agric. Food Chem. 2006, 54, 9496-9502. [CrossRef]

5. Alexi, N.; Fountoulaki, E.; Grigorakis, K. Quality of reared gilthead sea bream (Sparus aurata) during ice storage, as affected by dietary fish oil substitution; an instrumental and sensory designation approach. Aquac. Res. 2017, 48, 3817-3828. [CrossRef]

6. Mu, H.; Wei, Z.; Yi, L.; Liang, H.; Zhao, L.; Zhang, W.; Mai, K. Dietary fishmeal levels affect the volatile compounds in cooked muscle of farmed large yellow croaker Larimichthys crocea. Aquac. Res. 2017, 48, 5821-5834. [CrossRef]

7. Yuan, Y.; Wang, X.; Jin, M.; Jiao, L.; Sun, P.; Betancor, M.B.; Tocher, D.R.; Zhou, Q. Modification of nutritional values and flavor qualities of muscle of swimming crab (Portunus trituberculatus): Application of a dietary lipid nutrition strategy. Food Chem. 2020, 308, e125607. [CrossRef]

8. Azaria, S.; van Rijn, J. Off-flavor compounds in recirculating aquaculture systems (RAS): Production and removal processes. Aquac. Eng. 2018, 83, 57-64. [CrossRef] 
9. Zhang, X.; Wang, J.; Tang, R.; He, X.; Li, L.; Takagi, Y.; Li, D. Improvement of muscle quality of grass carp (Ctenopharyngodon idellus) with a bio-floating bed in culture ponds. Front. Physiol. 2019, 10, e683. [CrossRef]

10. Zhang, J.; Wang, G.; Xie, J.; Yu, E.; Yu, D.; LI, Z.; Zhang, K. Relationship between bacterial community composition and Ctenopharyngodon idella growth in periphyton substrate systems with different densities. J. Fish. China 2019, 43, 988-996.

11. Yu, E.; Fu, B.; Wang, G.; Li, Z.; Ye, D.; Jiang, Y.; Ji, H.; Wang, X.; Yu, D.; Ehsan, H.; et al. Proteomic and metabolomic basis for improved textural quality in crisp grass carp (Ctenopharyngodon idellus C.et V) fed with a natural dietary pro-oxidant. Food Chem. 2020, 325, 126906. [CrossRef]

12. Mao, D.; Zhang, K.; Ou, H.; Xie, J.; Wu, Y.; Huang, Z.; Wang, G.; Yu, D.; Yu, E.; Li, Z.; et al. Comparative analysis on flesh quality of grass carp (Ctenopharyngodon idellus) fed with two kinds feeds. Chin. J. Anim. Nutr. 2018, 30, 2226-2234.

13. Ruan, Q.; An, Y.; Chen, Z.; You, J.; Xiong, S. Effect of Short-Time Micro-Flow Water Treatment on Flavor Quality of Grass Carp Fish Meat. J. Food Sci. Technol. 2021, 03, 30-42.

14. Zhang, K.; Yu, D.; Li, Z.; Xie, J.; Wang, G.; Gong, W.; Yu, E.; Tian, J. Influence of eco-substrate addition on organic carbon, nitrogen and phosphorus budgets of intensive aquaculture ponds of the Pearl River, China. Aquaculture 2020, 520, 734868. [CrossRef]

15. Xu, L.; Yu, X.; Li, M.; Chen, J.; Wang, X. Monitoring oxidative stability and changes in key volatile compounds in edible oils during ambient storage through HS-SPME/GC-MS. Int. J. Food Prop. 2017, 20, S2926-S2938. [CrossRef]

16. Yi, C.; Li, Y.; Zhu, H.; Liu, Y.; Quan, K. Effect of Lactobacillus plantarum fermentation on the volatile flavors of mung beans. LWT 2021, 146, 111434. [CrossRef]

17. Dong, W.; Hu, R.; Long, Y.; Li, H.; Zhang, Y.; Zhu, K.; Chu, Z. Comparative evaluation of the volatile profiles and taste properties of roasted coffee beans as affected by drying method and detected by electronic nose, electronic tongue, and HS-SPME-GC-MS. Food Chem. 2019, 272, 723-731. [CrossRef] [PubMed]

18. Hiplot Platform. Available online: https:/ /hiplot.com.cn/ (accessed on 1 August 2021).

19. Wu, K.; Xie, J.; Wang, Q.; Ling, M.; Wu, J. Effect of Monascus Fermentation on Aroma Patterns of Semi-Dried Grass Carp. Food Nutr. Sci. 2019, 10, 923-936.

20. Giri, A.; Osako, K.; Ohshima, T. Identification and characterisation of headspace volatiles of fish miso, a Japanese fish meat based fermented paste, with special emphasis on effect of fish species and meat washing. Food Chem. 2010, 120, 621-631. [CrossRef]

21. Gu, S.; Wang, X.; Tao, N.; Wu, N. Characterization of volatile compounds in different edible parts of steamed Chinese mitten crab (Eriocheir sinensis). Food Res. Int. 2013, 54, 81-92. [CrossRef]

22. Zhuang, K.; Wu, N.; Wang, X.; Wu, X.; Wang, S.; Long, X.; Wei, X. Effects of 3 Feeding Modes on the Volatile and Nonvolatile Compounds in the Edible Tissues of Female Chinese Mitten Crab (Eriocheir sinensis). J. Food Sci. 2016, 81, S968-S981. [CrossRef]

23. Wang, Y.; Xu, P.; Wu, X.; Wu, X.; Wang, B.; Huang, Y.; Hu, Y.; Lin, J.; Lu, Z.; Li, G. GourdBase: A genome-centered multi-omics database for the bottle gourd (Lagenaria siceraria), an economically important cucurbit crop. Sci. Rep. 2018, 8, 3604. [CrossRef]

24. Geran, L.C.; Travers, S.P. Bitter-responsive gustatory neurons in the rat parabrachial nucleus. J. Neurophysiol. 2009, 101, 1598-1612. [CrossRef]

25. Zhou, X.; Chong, Y.; Ding, Y.; Gu, S.; Liu, L. Determination of the effects of different washing processes on aroma characteristics in silver carp mince by MMSE-GC-MS, e-nose and sensory evaluation. Food Chem. 2016, 207, 205-213. [CrossRef]

26. Goto, T.; Shimamoto, S.; Takaya, M.; Sato, S.; Takahashi, K.; Nishimura, K.; Morii, Y.; Kunishige, K.; Ohtsuka, A.; Ijiri, D. Impact on genetic differences among various chicken breeds on free amino acid contents of egg yolk and albumen. Sci. Rep. 2021, 11, 2270. [CrossRef]

27. Moretti, V.M.; Vasconi, M.; Caprino, F.; Bellagamba, F. Fatty Acid Profiles and Volatile Compounds Formation During Processing and Ripening of a Traditional Salted Dry Fish Product. J. Food Process. Preserv. 2017, 41, e13133. [CrossRef]

28. Guo, Q.; Yu, J.; Zhao, Y.; Liu, T.; Su, M.; Jia, Z.; Zhao, Y.; Mu, Z.; Yang, M. Identification of fishy odor causing compounds produced by Ochromonas sp. and Cryptomonas ovate with gas chromatography-olfactometry and comprehensive two-dimensional gas chromatography. Sci. Total Environ. 2019, 671, 149-156. [CrossRef] [PubMed]

29. Piveteau, F.; Le Guen, S.; Gandemer, G.; Baud, J.P.; Prost, C.; Demaimay, M. Aroma of Fresh Oysters Crassostrea gigas: Composition and Aroma Notes. J. Agric. Food Chem. 2000, 48, 4851-4857. [CrossRef] [PubMed]

30. Josephson, D.B.; Lindsay, R.C.; Stuiber, D.A. Variations in the occurrences of enzymically derived volatile aroma compounds in salt- and freshwater fish. J. Agric. Food Chem. 1984, 32, 1344-1347. [CrossRef]

31. Liu, Y.; Cheng, H.; Liu, H.; Ma, R.; Ma, J.; Fang, H. Fermentation by Multiple Bacterial Strains Improves the Production of Bioactive Compounds and Antioxidant Activity of Goji Juice. Molecules 2019, 24, 3519. [CrossRef]

32. Ma, R.; Liu, X.; Tian, H.; Han, B.; Li, Y.; Tang, C.; Zhu, K.; Li, C.; Meng, Y. Odor-active volatile compounds profile of triploid rainbow trout with different marketable sizes. Aquac. Rep. 2020, 17, e100312. [CrossRef]

33. Zhou, Y.; Wu, S.; Peng, Y.; Jin, Y.; Xu, D.; Xu, X. Effect of lactic acid bacteria on mackerel (Pneumatophorus japonicus) seasoning quality and flavor during fermentation. Food Biosci. 2021, 41, 100971. [CrossRef]

34. Song, X.F.; Yang, X.H.; Huang, Z.T. Advances in Studies on Nitrate Toxicity to Fish [J]. Period. Ocean Univ. China 2019, 49, 34-41.

35. Smallbone, W.; Cable, J.; Maceda-Veiga, A. Chronic nitrate enrichment decreases severity and induces protection against an infectious disease. Environ. Int. 2016, 91, 265-270. [CrossRef] [PubMed]

36. Miao, L.H.; Lin, Y.; Pan, W.J.; Huang, X.; Ge, X.P.; Zhou, Q.L.; Liu, B.; Ren, M.C.; Zhang, W.-x.; Liang, H.-l.; et al. Comparative transcriptome analysis reveals the gene expression profiling in bighead carp (Aristichthys nobilis) in response to acute nitrite toxicity. Fish Shellfish Immunol. 2018, 79, 244-255. [CrossRef] 
37. Yu, J.; Wang, Y.; Xiao, Y.; Li, X.; Xu, X.; Zhao, H.; Wu, L.; Li, J. Effects of chronic nitrate exposure on the intestinal morphology, immune status, barrier function, and microbiota of juvenile turbot (Scophthalmus maximus). Ecotoxicol. Environ. Saf. 2021, 207, 111287. [CrossRef]

38. Kim, J.H.; Kim, S.K.; Hur, Y.B. Toxic effects of waterborne nitrite exposure on antioxidant responses, acetylcholinesterase inhibition, and immune responses in olive flounders, Paralichthys olivaceus, reared in bio-floc and seawater. Fish Shellfish Immunol. 2020, 97, 581-586. [CrossRef] [PubMed]

39. Li, Z.S.; Ma, S.; Shan, H.W.; Wang, T.; Xiao, W. Responses of hemocyanin and energy metabolism to acute nitrite stress in juveniles of the shrimp Litopenaeus vannamei. Ecotoxicol. Environ. Saf. 2019, 186, 109753. [CrossRef] [PubMed]

40. Dolomatov, S.; Zukow, W.; Hagner-Derengowska, M.; Kozestanska, M.; Jaworska, I.; Nalazek, A. Toxic and physiological aspects of metabolism of nitrites and nitrates in the fish organism. J. Health Sci. 2013, 3, 68-91.

41. Ping, L. Effects of compound feed with oaked beans and embrittlement on growth performance and muscle quality in Ctenopharynodon idellus. China Feed 2017, 18, 33-37.

42. Mao, D. Comparative Study of Effect of Two Kinds of Feed on Body Characteristics and Muscle Quality of Grass Crap (Ctenopharyngodon Idellus); Dalian Ocean University: Dalian, China, 2018. 